Bradley M. Porath

Citrus College

One of the most vexed topics in Hume scholarship is his position regarding personal identity. In this paper, 1 will demonstrate that Hume presents a positive and constructive view of the self in his discussion of the indirect passions found in Book II of $A$ Treatise of Human Nature (1739).' For Hume the personal indirect passions of pride and humility are constitutive of, or are equivalent to, the impression of the self. Pride and humility form a continuum of affective states along which conscious apperception moves. Each conscious moment involves the feeling of some degree of pride or humility, and this feeling always has reference to some conception of self. And in a similar fashion, the external indirect passions, love and hatred, are constitutive of, or equivalent to, our knowledge of other minds. These four types of passions are generic, and are involved in most of our higher-order affective states and purposeful behavior. They are directed by an "original" capacity of the mind to the two major areas of concern we experience during most of our waking hours. Pride and humility are involved with our constant desire for our own personal well- being and the improvement of our own particular situation. Love and hatred are involved with our daily interaction with other human beings and society at large.

Furthermore, these indirect passions are not mere perturbations of the soul; instead, they result from the interaction of the two components of human consciousness which Hume distinguishes as impressions and ideas. I will follow D.G.C. MacNabb's ${ }^{2}$ view that the distinction between impressions and ideas is that between the given and what is thought about. As Hume expresses it, it is the "the difference betwixt fecling and thinking." (T. p.2 / cf. Abstract appended to Treatise p.647) This

In this paper, the primary sources are indicated by the following abbreviations: (T.) David Hume, 1 Trealise of Iluman Nature L.A. SelbyBigge ed. 2nd ed. revised by P.H. Nidditch. (Oxford: At The Claredon Press, 1980). I have included with block quotes from the Treatise the book, part, and section number to aid in identification. // (1E.) David Hume, Enquiry Concerning Human Underslanding L.A. Selby-Bigge ed. 3rd. ed. revised by P.H. Nidditch. (Oxford: Clareton Press, 1982). // (D.P.) David Hume, "A Dissertation on the Passions" in Essays: Moral, Political, and Lilerary. 2 vols. T.H. Green and T.H. Grose eds. (London: Longmans, Green, and Co., 1882. vol 2; reprint ed., n.p. Scientia Verlag Aalen, 4 vols., 1964).

2D.C.C. MacNabb, David Ilume: Ilis Theory of Knowlentge and Morality (London: Hutchinson's University Library, 1951), pp. 25 - 32. 
interpretation avoids the difficulties involved in viewing ideas as weaker images or copies of preceeding impressions. For Hume most ideas, except those involved in visual imagination, are non-eidetic: they exist but are nowhere. (T. p.235)

The course of British philosophy from Berkeley to Hutcheson witnesses the successful obliteration of the distinction between primary and secondary qualities. Hume follows Hutcheson's view that secondary qualities are constitutive of primary qualities. Thus secondary qualities are known as impressions and primary qualities are known only as ideas. (T. p.366, Pp.225-31 // 1E \#122 pp.154-55). This crucial feature of Hume's epistemology is documented by David Fate Norton. ${ }^{3}$ Thus for Hume each moment of consciousness is a composite of both impressions and idea.

To put this issue in better perspective, we must note that there are two widely different epistemological theories that are attributed to Hume. These are, on the one hand, idealism or an extreme form of phenomenalism, and on the other, a physiologically based interactionist theory. Hume's epistemological position, in fact, steers an even course between these two widely different theories. Hume's methodological position is phenomenalism, and thus he must restrict his investigation of human nature to those perceptions which appear before the mind. (T. p.84) But based on common sense, Hume adamantly believes in the existence of a self-existing external world, which includes physical objects and one's own physical body. (T. p.187/cf p.298) Throughout the Treatise we find a certain tension between Hume's acceptance of both these theories which ultimately results in his famous "lament" (T. p.636) regarding his inability to resolve the question of personal identity. found in the Appendix (1740).

Some commentators have wrongly attributed to Hume an "atomic theory of perception," resulting in confusion about his epistemological position. This "atomic view" may be distinguished into a weaker and stronger version which have a tendency to be confused. The weaker version states that our concepts or ideas are eidetic images or reified mental particulars. In contrast, the stronger or metaphysical atomism, maintains both that physical objects are made of atomic particles, and that the mind is composed of a grouping of individual perceptions. The stronger version suggests that perceptions, like physical atoms, may exist outside the mind, and even influence or become perceptions in another mind. In the most extreme view both these physical and mental atoms are viewed as being in essence the same, and as differing only in being related to either an object or a mind. I would maintain that in the numerous instances where Hume claims that all our perceptions are "...distinguishable, and separable from each other, and may be separately

${ }^{3}$ David Fate Norton, David Ilume: Common-sense Moralist, Sceptical Metaphysician (Princeton, N.J.: Princeton University Press, 1982), pp. 78-82. 
consider'd, and may exist separately...," (T.p.252) he is making a logical rather than metaphysical claim. That is, they may be considered separably by a "distinction of reason" which does not entail their distinct existence. (T. p.25) Oddly enough, it seems that both the weak and strong versions of the "atomic" view do not require much effort to be recast in representational or mechanical terms.

I must stress that for Hume ideas and/or impressions are not reified mental particulars or images which are representatives of some external reality. Our conscious apprehension maintains a synthetic unity over time which can not be explained in terms of a mechanical, representational, or atomistic epistemology. In this regard, I would maintain that Hume's theory of mind is more modern than is usually supposed.

This thesis will provide an adequate solution to what numerous commentators, principally Norman Kemp-Smith have declared to be an obvious contradiction between Book I and Book II of the Treatise. This contradiction is based on the fact that in Book I, "Of the Understanding," in the section entitled "On Personal Identity," Hume states that there is not a specific impression of the self from which we derive the idea of the self. In contrast, Hume states in Book II, "Of the Passions," that "the idea or rather impression of ourselves is always intimately present with us." (T. p.317) This quotation is just one of a number of statements found in Book II which seem to be at odds with what is taken to be Hume's official position in Book $I$. Kemp-Smith has focused on this alleged contradiction as textual support for his wider thesis that Hume first wrote Book II of the Treatise under the influence of Hutcheson's moral teachings and that Book $I$ is the unique and distinctively Humean result of his more mature reflections. My purpose is to resolve this contradiction by showing that the two differing statements in Book I and II are different aspects of Hume's comprehensive view of human nature.

In Book I, in the section "On Personal Identity," Hume distinguishes between these two aspects as follows:

What then gives us so great a propension to ascribe an identity to these successive perceptions, and to suppose ourselves possest of an invariable and uninterrupted existence thro' the whole course of our lives? In order to answer this question, we must distinguish betwixt personal identity, as it regards our thought or imagination, and as it regards our passions or the concern we take in ourselves. $(I, 4, v i$ p.253)

For the sake of convenience, we may label these two aspects, respectively: philosophical and psychological. Hume emphasizes that it is "...the first [which] is our present subject" in this section of Book I. The

'Norman Kemp Smith, The Philosophy of David Ilume (London: Macmilliam and Co. limiled., 1941). 
philosophical aspect involves metaphysical and epistemological questions regarding the self and the origin and application of the concepts of 'personal identity' and the 'self.

Hume does not deny that the term 'self is meaningful; instead, he claims that it does not denote just one unique impression, but it refers to a random grouping of related or similar impressions. Specifically, the point at issue is whether we are able to derive only a "fictional idea" or cunceptualization of the self, or whether this idea refers to, or is based on some unique "felt quality" or impression. Accordingly, Hume states that upon introspection the self appears to be just a "bundle or collection of perceptions." (T. p.252)

In contrast, the psychological aspect covers our desire for selfimprovement in our daily affairs. In Book II, Hume's purpose is to follow up on this distinction and examine the psychological aspect of personal iderntity. Hume does this is in Part 1 of Book II where he indicates that the personal indirect passions of pride and humility are related to the "idea of self."

Hume adopts his usage of the terms pride and humility from Hobbes 5 and Mandeville 6 who both emphasize that these passions play, respectively, a positive and negative motivational role in human behavior. According to Hobbes, pride or glory was the natural emotion for a noble and magnanimous man as he triumphed in his endeavors and acquired power, and humility was "the passion contrary to glory, proceeding from apprehension of our own infirmity..." 7

Thus it is a mistake to view these indirect passions in their narrow everyday usage. This cannot be overly stressed since even Kemp-Smith has indicated that the indirect passsions "do not play a distinctive part" 8 in Ilume's system. But in contrast, I hope to show that Hume in his examination of these indirect passions presents a positive portrait of the human mind. Thus in Book II, Hume's purpose is to examine these higher-order affective states.

Ilume's examination of pride and humility in I'art 1, Book II can be divided into three topic areas. The first area, which includes sections ii and iii, is an empirical examination of these two passions in which Hume defines his terminology. In the second area, sections iv 10 vi, Hume presents his theory of the "double relations of impressions and ideas" as the governing principle for the operation of these passions. In section vi, llume presents the limitations of this system. In the final area, which comprises sections vii to xii, Hume attempts to apply his system to the

${ }^{5}$ D.D. Raphacl ed., British Moralists 1650-1800 2 vol. (Oxford: At the Clarendon P'ress, 1969), pp. 6-7.

6Ilbid., pp. 232-236.

7lbid., p. 7.

SSmith, p. 160. 
various causes which produce these passions. These include: a concern for our moral character, our health and physical appearance, our social standing and family relations, our property, and reputation. In this paper I will summarize my examination of the first two topic areas only.

In the first topic area, Hume presents an informal definition for pride and humility and indicates that these passions have the same object: the "...self, or that succession of related ideas and impressions, of which we have an intimate memory and consciousness." (T. p.277) Because these passions are directly contrary, the self is a necessary though not sufficient condition for their existence; in addition, they require a separate determining "cause." (T. p.278 cf p.287)

Hume next distinguishes the cause of these passions into two component parts, which he will later describe as "suppos'd properties." (T. p.285) These are the "...quality, which operates, and the subject, on which it is plac'd." (T. p.279) Ilume describes the full operation of the passions thus:

Here the object of the passion is himself, and the cause is the beautiful house: Which cause again is sub-divided into two parts, viz. the quality, which operates upon the passion, and the subject, in which the quality inheres. The quality is the beauty, and the subject is the house, consider'd as his property or contrivance. Both these parts are essential, nor is the distinction vain and chimerical. (11,1,ii p279)

The quality of the cause is its sensible characteristics, the subject is its conceptual nature. In our conscious apprehension, both these aspects are united. To retain the spirit of Hume's theory, I will adopt his use of these four terms: object, cause, quality, and subject. As this exposition proceeds, the application of these terms will become sufficiently clear.

In the next topic area in Part 1, Book II, which covers sections iv to vi, Hume attempts to prove that his theory of "the double relation of impressions and ideas" accurately represents the operation of our passions. Relations which Hume describes as "an easy transition" between ideas are central to his theory of mind. (T. p.220) In kerping with his general psychology, these relations operate on the two levels of ideas and impressions, or as indicated above, thought and feeling.

In order to this we must reflect on certain properties of human nature, which tho' they have a mighty influence on every operation both of the understanding and passions, are not commonly much insisted on by philosophers. The first of these is the association of ideas, which I have so often observ'd and explain'd....

The second property I shall observe in the human mind is a like association of impressions. (II, 1,iv p.283) 
Hume divides thought, or the conscious apprehension of ideas, into two categories: imagination and the understanding. The imagination involves both our awareness of ideas which are produced spontaneously in response to some present impression and also the formation of our concepts.

When I oppose the imagination to the memory, I mean the faculty, by which we form our fainter ideas. When I oppose it to reason, I mean the same faculty, excluding only our demonstrative and probable reasoning. When 1 oppose it to neither, 'tis indifferent whether it be taken in the larger or more limited sense, or at least the context will sufficiently explain the meaning. (I,3,x p.118-footnote, cf II,2, vii p.371-footnote)

Therefore, the imagination involves the habitual association the mind makes between various ideas, and between impressions and ideas. It helps extend our knowledge beyond our present impressions through the formation of beliefs, concepts, and certain general rules. (T. pp.197-199) Thus the imagination serves as the foundation for our reasoning processes.

Hume in Book I distinguishes also between "natural" and "philosophical" relations. Our ideas associate, or move from one to another, in our imagination, according to the three natural relations of resemblance, contiguity, and causality. In contrast, for Hume, the association of ideas by means of philosophical relations are willed, and thus are the basis of our reasoning abilities. (T. p.13-15) Among the later, Hume lists the relation of identity which can be applied to objects in the world and to ourselves. (T. p.189-218) According to Hume the will is "...nothing but the internal impression we feel and are conscious of, when we knowingly give rise to any new motion of our boxdy, or new perception of our mind." (T. p.399)

Furthermore, Hume maintains there is a "... like association of impressions lof reflection-i.e. the passions (T. p.7, pp.275- 76)l, operating through resemblance, or a similarity of hedonic quality. (T. p.283) Hume stales that an additional factor governing the flow of our emotional states is a similarity in "tendency or direction." (T. p.381-385)

Although there is this natural inertia in both our ideas and impressions, this does not prevent either from displaying radical shifts in our awareness. Through the philosophical relations, our imagination and our reasoning abilities are given free rein. Our affective states may be changed either by our brcoming aware of some new situation, or by the imposition of some idea.

But in general there is the tendency for our awareness to be fixed on one type of affective state or passion at one time. Hume indicates that 
when different passions compete for our attention three different situations may occur: (1) the differing passions may exist successively (2) the stronger passion will prevail (3) a third passion may be produced-e.g.hope or fear arise from the alternating joy and grief experienced when one considers the cause of the passions to be probable. Hume graphically describes these three alternatives thus:

The influence of the relation of ideas is plainly seen in this whole affair. If the objects of the contrary passions be totally different, the passions are like two opposite liquors in different bottles, which have no influence on each other. If the objects be intimately connected, the passions are like an alcali and an acid, which, being mingled, destroy each other. If the relation be more imperfect, and consists in the contrary views of the same object, the passions are like oil and vinegar, which, however mingled, never perfectly unite and incorporate. (II,3,ix p.443/cf D.P.p.143)

The flow and interaction of our passions depends upon the ideas which we conceive along with the violence of the prevailing passion. In particular, the four indirect passions display both the first and second alternative described above. Because pride is opposed to humility, and love to hatred, in regard to their respective objects, the self or other minds, it is required that there is some external cause or relevant idea to produce any of these indirect passions. The manner in which we view the quality of the cause determines which alternative takes place. If the cause has opposing qualities it may be the source of mental conflict. It is impossible for a man to be both proud and humble, or to love and hate the same person, at the same time. Rather these passions will occur alternatively as we reflect upon the positive or negative qualities of the "subject." At some point, this mental conflict will be resolved and then the predominate passion will prevail.

As a concluding remark in section iv Hume states:

In the third place, 'tis observable of these two kinds of association, that they very much assist and forward each other, and that the transition is more easily made when they both concur in the same object. Ithat is, "cause" e.g. the bad qualities of an enemyl... Those principles, which forward the transition of ideas, here concur with those, which operate on the passions; and both uniting in one action, bestow on the mind a double impulse. The new passion, therefore, must arise with so much greater violence, and the transition to it must be render'd so) much more easy and natural. (II,1,iv pp.283-84) 
Our ideas and impressions unite in one act of consciousness, which then becomes more intense in our awareness, and thus facilitates the transition to other similar states of emotion.

In section $v$, Hume's purpose is to apply these general considerations regarding the flow of our emotions to the personal indirect passions, pride and humility. He must show how these two types of association combine in one conscious act to form these passions. Thus he must show how these two types of association operating on two parallel levels contribute to the generation of these emotional states.

The "suppos'd properties" of the cause are the two parts, subject and quality, distinguished above. On the level of ideas or thought the "subject" which causes the passion is related to its "object." The possessions and character of another unrelated person never cause us to experience pride or humility, though our own possessions and character do cause such ferlings. (T. p.285)

On the level of impressions or feelings the "quality" of the "cause" produces either pleasure or pain. Thus ".... Humel takes it for granted at present, without farther proof, that every cause of pride, by its peculiar qualities, produces a separate pleasure, or of humility a separate uncasiness." (T.p.285) Hume describes this quality as "independent" or "separate," which means it is capable of producing pleasure or pain when considered objectively. These qualities are assumed to be "natural," based upon environmental and societal conditions, which are universally acknowledged and sought after by all mankind.

Hume turns next to the two "establish'd properties" of the passions themselves, which he stresses are "original" features of a person's biological and psychological make-up. These "establish'd properties" are that pride and humility always direct our attention to our self; and that these passions are in essence pleasant or painful sensations. (T. p.286) When Hume compares the "establish'd properties" of the passion with the "suppos'd properties" of the cause he states:

... I immediately find, that taking these suppositions to be just, the true system breaks in upon me with an irresistible evidence. That cause, which excites the passion is related to the object, which nature has attributed to the passion; the sensation, which the cause seperately produces, is related to the sensation of the passion: From this double relation of ideas and impressions, the passion is deriv'd. The one idea is easily converted into its cor-relative; and the one impression into that, which resembles and corresponds to it: With how much greater facility must this transition be made, where these movements mutually assist each other, and the mind receives a double impulse from the relations both of its impressions and idcas? (II,1,v p.286-87) 


\section{HUME'S POSITIVE THEORY OF PERSONAL IDENTITY 155}

Finally, Hume suggests that the operation of these passions may have a physiological basis. (T. p.287)

Having laid out the textual basis for Hume's theory of the double relation of impressions and ideas, we must now turn our attention to one final issue. Here I will contrast two interpretive schemata for the operation of the passions. I wish to call the schema which has achieved currency among most commentators 9 the 'traditional' one, and the schema I wish to advance 'hedonic'. In my opinion, most of the criticisms that have been leveled at Hume's theory of the passions have been based on the acceptance of the 'traditional' schema, and as such have been misdirected. We must note, though, that these schemata do not do justice to the complexily and dynamic nature of our higher-order affective states; they are just useful conceptual devices.

\section{The Tradilional Schema}

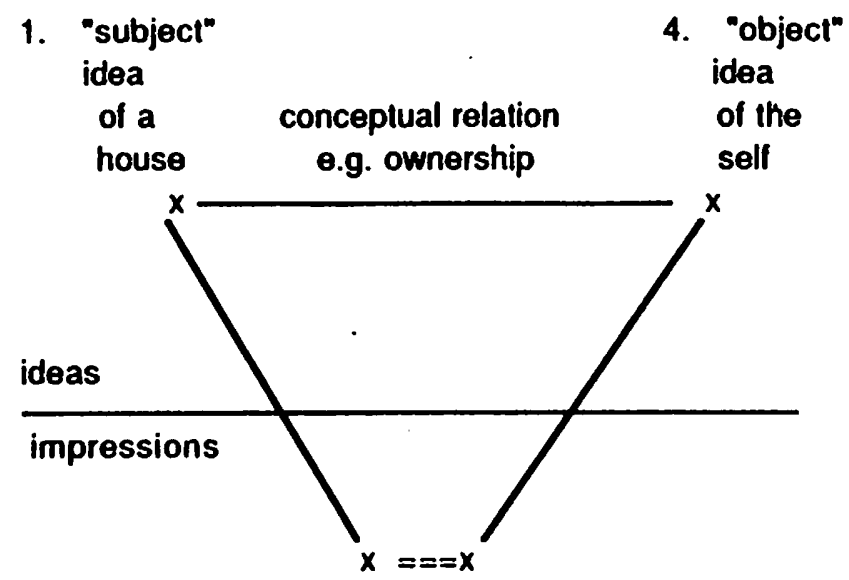

2. Pleasure 3. Pride

9In addition to Kemp-Smith the following scholars present a version of the traditional schema:

Pall S. Ardal, Passion and Value in Hume's Treatise (Edinburgh: At the University Press, 1966), p. 26.

Alfred B. Glathe, Hume's Theory of the Passions and of Morals: A Study of Books II and III of the "Treatise." (Berkeley, Ca: University of California Press, 1950), pp. 22-39.

Nicholas Capaldi, David Ilume: Newtonian Philosopher (Princeton, N.J.: Princeton University Press, 1982), pp. 132-34. 
Norman Kemp Smith, in his monumental work, advances a version of the 'traditional' schema which he describes as a:

... four-stage sequence whereby (1) starting from the idea of this complex 'subject', into which the idea of the self enters as a component, the mind is carried (2) in and through a separate 'sensation of pleasure or pain' and (3) through the consequent passion of pride or humility, (4) back to the idea of the self. The four stages, he insists, are distinct and separate-the sensation of pleasure for instance is, he maintains, distinct from the passion of pride, just as truly as the passion in itself simple, is distinct both from its exciting 'subject' and from its 'object'. And it is because he regards these stages as distinct that he is cominitted to the task of explaining why the steps thus follow in sequence, and how in so doing they combine to support and reinforce one another. ${ }^{10}$

There are three distinct features of this description: (1) that the component stages of the process are distinct in some experiential sense (2) that the stages occur in discrete steps over time, which involves a number of questions, including how these stages are related, both logically-that is, in our conception-and in their actual operation. And (3) that the first slage involves the "idea of the subject," which is supposed to initiate the process.

From the above textual analysis, it is evident that none of these thrce features can be read into Hume's stated position; thus the 'traditional' schema does not adequately represent his views in this regard. In regard to (1) and (2) two points need to be made. First, it is perfectly clear that according to Hume the experience of an indirect passion is indistinguishable from its hedonic quality. (T. p.286) Second, it seems difficult to conceive what it means to be able 10 distinguish an act of conception from its surrounding impressional states, except in retrospect and on a purely theoretical basis. Hume indicates that even upon the closest introspection such conceptual acts or relations will appear entirely hidden.

Tis evident, that the association of ideas operates in so silent and imperceptible a manner, that we are scarce sensible of it, and discover it more by its effects than by any immediate fecling or perception. It produces no emotion, and gives rise to no new impression of any kind, but only modifies those ideas, of which the mind was formerly possess'd, and which it cou'd recal upon occasion. (II,1,ix p.305)

${ }^{10}$ Smith, Pp. 181-82. 


\section{HUME'S POSITIVE THEORY OF PERSONAL IDENTITY 157}

In regard to (3) for the most part our experience of either of these indirect passions is the result of a present impression, rather than the result of some remembered idea. We are directly acquainted with the cause of our passions. For example, when we observe our own home we become aware, not only of its basic sensible qualities but also its aesthetic qualities as well. And at the very same time, we conjoin these virtuous qualities, with the notion of ownership, to produce the indirect passion itself. In our experience the transition from sensible awareness to its corresponding emotional state is smooth and indistinguishable.

Here I wish to present my interpretive schema, which I call 'hedonic', since it emphasizes the immediate apprehension of pleasure or pain in our sensible awareness, which, as Hume stresses is in essence the same fceling as the passion itself.

\section{The Hedenic Schema}

2. "Subject" the idea of a house
4. "Object" the idea of the self

e.g. ownership

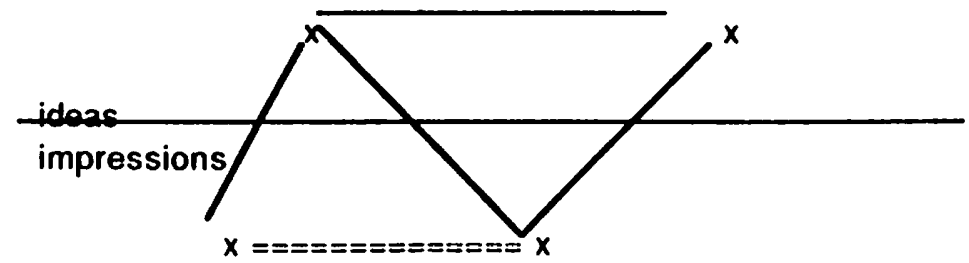

1. "Quality"

Pleasure: a synthesis of both sensible and aesthetic impressions i.e. the shape and color of the house along with its beauty
3. Pride: Impression of Reflection

i.e. the passion as felt

To emphasize that these four stage blend indistinguishably in our awareness, I have added two overlapping circles, which delineate the 
"suppos'd properties" of the cause from the "established properties" of the passion.

Thus the "cause" in our awareness is a composite of both its sensible qualities and the concept of the "subject" which it occasions in our understanding. Here we should distinguish this psychological act from the fact that in most instances, the cause of the passion is some external selfexisting "subject" or a virtuous quality considered in the abstract. In the latter case virtuous qualities are aspects of a person's very being, and thus can not be projected on some external existence; nevertheless, we still are able to distinguish between their felt qualities and their conceptual nature. Ilere I have adopted Hume's wider definition of virtue, which includes not only what are normally considered moral qualities, but also natural abilities, talents, social graces, and personal hygiene. (T. pp.606-14) Thus in the case of the virtuous qualities a person possesses, we find both some visceral fecling conjoined with an abstract concept of the virtue, along with some knowledge regarding its justification. The more unique the cause of the passion is, the greater is its requirement to be conceptualized, verbally or otherwise, and justified to oneself. In our daily affairs, these virtues are intensified through a sympathetic appreciation of how others perceive us. (T. p.316) These virtuous qualities are aspects of personal character and do not exist externally, except in the opinions of others and in virtuous actions, which in themselves are effects and secondary.

I have connected the "suppos'd properties" of the "cause" to the "established properties" of the passion by a pair of dashed lines. This indicates the parallel action of the two levels of association operating between ideas on the one hand, and impressions on the other. The idea of the "cause/subject" is joined conceptually with the idea of the self as the one who owns, possesses, or is otherwise related to it. The "cause/quality", or capacity for producing pleasure or pain, is in essence the unique feeling of the passion. According to Hume, our feelings of pleasure and pain are equivalent to the positive or negative evaluation we give our particular situation and involves, not only gross sensible feelings, but also our moral and aesthetic tastes. (T. p.472)

Again, it should be emphasized that the pleasure or pain, the "cause" produces is not independent or separate, as a distinguishable sensible element, but rather constitutes the very essence of the passion itself. Indeed, it is difficult to conceive of any affective state which was perfectly indifferent and did not possess some measure of either pleasure or pain, especially when compared to some other point along the scale.

Finally, I have placed a circle to comprehend both the "establish'd properties" and to stress that both are component aspects of a single act of conscious apperception. Each moment of consciousness is a simple unity, and inherits all the preceding moments. The idea of the self is not some distinct, abstract, or metaphysical concept, as some commentators seem to believe, but a vital part of the complete emotional state. Thus to 
distinguish and separate our ideas or concepts from their concurrent affective states, as the 'traditional schema' suggest, is to ignore the importance of the dynamic interaction between these two levels of mental operation. The affective quality or feeling of either pride or humility, unites in one conscious act with our conception of the self and its related causes. Thus pride and humility are forms of self-valuation which invariably direct our attention to ourselves and vary according to how we conceive of our various virtuous qualities and social situation. The idea of the self is constituted out of the causes of pride or humility which are conceptually linked to it. To paraphrase Hume: "...were all lourl perceptions remov'd..." and we had no awareness of our property, our accomplishments, our natural abilities, our physical appearance, our virtues, our reputation, our health, our friends and relations, it would be hard to "...conceive what is farther requisite to make (us] a perfect nonentity." (T. p.252) Without such personal connections, our life would be empty and devoid of meaning. Thus our idea of self, as experienced in our practical daily affairs, is not an innate spiritual entity; it is the result of all these connections held together in our understanding, by memory and causal inference (T. pp.261-62), and facilitates the ease of transition among the natural and philosophical relations.

Ourself, independent of the perception of every other object, is in reality nothing: For which reason we must turn our view to external objects; and 'tis natural for us to consider with most attention such as lie contiguous to us, or resemble us. But when self is the object of a passion, "tis not natural to quit the consideration of it, till the passion be exhausted; in which case the double relations of impressions and ideas can no longer operate. (II,2,iii pp.340-41)

I hope that, in what has preceded, I have adequately covered all three features that the 'traditional' schema suggests, as indicated above. First, the four stages are not perceived separately, but rather are distinguished retrospectively by a "distinction of reason." (T. p.25) Second, the'se four stages occur nearly instantaneously and all unite in one complete act. (hur impressions and ideas are combined together to form our basic conscious awareness. Thus pride and humility are not only impressions or simple: perturbations of the soul, but rather involve complex evaluative judgments regarding the self. And lastly, the indirect passions are occasioned, for the most part, by present states of sensible awareness, rather than by remembered ideas.

Finally, as conclusive textual support for this thesis, it should be noted that every time Hume mentions "the double relation of impressions and ideas," both aspects are in the plural. This indicates that the first stage of the operation requires certain impressional qualities, along with some idea. These impressional qualities involve the indefinable moral and 
aesthetic judgments that constantly attend our sensible awareness of the environment. Hume, in concluding section v, makes this explicitly clear. He states that the first stage of the operation is similar to his explanation of belief, "...which we form from causation..." (T. p.289 cf p.78), that he believes he has proved in Book 1 . Hume defines belief as ".... A LIVELY IDEA RELATED TO OR ASSOCIATED WITH A PRESENT IMPRESSION." (T. p.96) Therefore, we are able to apply certain conceptual judgments in regard to our overall sensible awareness. For example, from the plethora of sensible and aesthetic qualities, we are immediately able to distinguish and judge that their cause is a beautiful house, which we further believe to be a self-existing entity and over which its owner wields some causal authority.

Therefore, for Hume, the continuum of affective states ranging from pride to humility are constitutive of, or equivalent to the impression of self. This thesis provides a number of useful insights regarding Hume's overall philosophical enterprise in the Treatise and, most important, helps to put Hume's statements in Book I regarding personal identity in proper perspective. His purpose is to attack the belief that we are acquainted through introspection with some unique and indefeasible impression, or sensible awareness of the self. Hume asserts, instead, with his famous "bundle metaphor" that we are acquainted with a variety. of random and disparate perceptions which together constitute conscious apprehension.

Most commentators focus their attention on the negative and critical tone of this "bundle metaphor" and thus overlook the positive and constructive aspects of Hume's psychology. They assume that Hume, in presenting this "bundle metaphor," is recommending some version of the 'atomic theory of perception' as indicated above. But the result is, in essence, an incomprehensible interpretation of his theory of mind.

Therefore, these commentators ${ }^{11}$ direct their attacks against this radical interpretation of Hume's psychology to make their work easier. In particular, they question Hume's belief that the natural relations of "resemblance and causation" provide the unity which we experience in our

"The following scholars have attributed some version of the "atomic theory of perception" to Hume: 26.

Barry Stroud, Hume (London: Routledge \& Kegan Paul, 1977), pp. 124-

Cavendish, A.P. (Basson, A.H. psued. 1958), David Hume (New York: Dover Publications, inc., 1968), pp.132-33.

Ayer A.J., Hume Past Master's Series (New York: Hill and Wang, 1980), Pp.52-54.

Stroud and Cavendish argue, respectively, that the relations of resemblance and causation are insufficient to provide the unity which we feel in our conscious apperception. Ayer presents a similar view. 


\section{HUME'S POSITIVE THEORY OF PERSONAL IDENTITY 161}

consciousnesss. (T. p.260) These commentators conclude that, because Hume subscribes to the 'atomic theory', he requires some further principle beyond just resemblance and causation to unite these separate free-floating atomic perceptions into one complete act of consciousness. They assert that this 'principle of individuation' is either some spiritual substance, or results from some physiological process. However, I believe, Hume would be sceptical of both these forms of explanation, since both go beyond the phenomena of our perception. Although both these forms of explanation are plausible, they are at best hypotheses which rely upon metaphysical and hence unknowable principles.

I would, instead, assert the more modest claim, that this 'principal of individuation' is the result of our intelligent and purposeful interaction with the world found in our higher-order affective states. This psychological necessity is a basic fact of our existence which is impossible to further dissect and analyze. This conclusion is consistent with the phenomenalistic portrait of the human mind which Hume presents in Book II. Thus it is a mistaken belief that the mind requires some additional 'principle of individuation' beyond that which is experienced daily in our practical goal-oriented behavior.

The "bundle metaphor" makes a logical and epistemological claim rather than a metaphysical and ontological one. Hume's purpose is to show that personal identity is not derived from a single, unique, and invariable impression. It is, in fact, an abstraction based on our acquaintance with all of our perceptions. Hume indicates that identity is a philosophical relation which in essence is the arbitrary association of ideas by our reasoning capacities. The identity which we attribute to the mind is a "fictitious one" derived through our faculties of memory, imagination, and reason. (T. p.259)

Later in Book $I$, in the section "On Personal Identity," Hume indicates that his preferred metaphor for the identity of our conscious apprehension is a nation-state.

Our impressions give rise to their correspondent ideas; and these ideas in their turn produce other impressions. One thought chaces another, and draws after it a third, by which it is expell'd in its turn. In this respect, I cannot compare the soul more properly to any thing than to a republic or commonwealth, in which the several members are united by the reciprocal ties of government and subordination, and give rise to other persons, who propagate the same republic in the incessant changes of its parts. And as the same individual republic may not only change its members, but also its laws and constitutions; in like manner the same person may vary his character and disposition, as well as his impressions and ideas, without losing his identity. Whatever changes he endures, his several parts are still connected by their relation of causation. And in this view our identity 
with regard to the passions serves to corroborate that with regard to the imagination, by making our distant perceptions influence each other, and by giving us a present concern for our past or future pains and pleasures. (I,4,vi p.261)

This analogy with a political entity is a much more sophisticated portrait of the mind than that provided by the "bundle metaphor." Thus our notion of the self results from the mind's ability to conceive and apply abstract ideas, or interpretive concepts, to the unity we feel is ever-present in our conscious awareness. Hume's view of personal identity, in this section, in no way denies or contradicts the belief that we are intimately acquainted with the unity of our conscious life. His purpose, instead, is to deny that this idea of the self is based upon some introspective awareness of a unique and unchanging impression.

But Hume himself in the Appendix to the Treatise, expresses his disillusionment over this whole question regarding personal identity. On the one. hand, he realizes that the conscious unity found in our higherorder affective states requires a "real connexion" (T. p.636), or "principal of individuation', among our various perceptions. On the other hand, he is unwilling to abandon his phenomenalistic methodology which prevents him from speculation as to its nature. He realizes that such a "real connexion" is beyond the phenomena of our conscious perception and thus is unknowable. The result, therefore, is his famous "lament."

Most philosophers seem inclin'd to think, that personal identity arises from consciousness; and consciousness is nothing but a reflected thought or perception. The present philosophy, therefore, has so far a promising aspect. But all my hopes vanish, when I come to explain the principles, that unite our successive perceptions in our thought or consciousness. I cannot discover any theory, which gives me satisfaction on this head.

In short there are two principles, which I cannot render consistent, nor is it in my power to renounce either of them, viz. that all our distinct perceptions are distinct existences, and that the mind never perceives any real connexion among distinct existences. Did our perceptions either inhere in something simple and individual, or did the mind perceive some real connexion among them, there wou'd be no difficulty in the case. For my. part, 1 must plead the privilege of a sceptic, and confess, that this difficulty is too hard for my understanding. I pretend not, however, to pronounce it absolutely insuperable. Others, perhaps, or myself, upon more mature reflection, may discover some hypothesis, that will reconcile those contradictions. (T. Appendix pp.635-36) 


\section{HUME'S POSITIVE THEORY OF PERSONAL IDENTITY 163}

Few philosophers are willing to admit publically to their mistakes and inabilities, and thus we must conclude that "Hume's lament" is indicative of rare intellectual honesty on his part. If we are to advance in our philosophical inquiries we must adopt a similar honesty and fairness in our criticism of past thinkers. Therefore, to interpret Hume correctly, and to recognize where he makes his mistakes, we must learn to appreciate both the negative and positive aspects of his theory of personal identity. It is only then that we will be able to make some progress in our own philosophy. 